Supplementary Information for-

\title{
Electron transport in multi-dimensional fuzzy graphene nanostructures
}

Raghav Gargł, Devashish P. Gopalan , Sergio C. de la Barrera ${ }^{\ddagger}$,Hasnain Hafiz", Noel T. Nuhferł, Venkatasubramanian Viswanathan $\|$, Benjamin M. Hunt ${ }^{\dagger},{ }^{*},{ }^{*}$, Tzahi Cohen-Karnit,,${ }^{*}$

${ }^{\dagger}$ Department of Materials Science and Engineering, Carnegie Mellon University, Pittsburgh, Pennsylvania 15213, United States

* Department of Physics, Carnegie Mellon University, Pittsburgh, Pennsylvania 15213, United States

I| Department of Mechanical Engineering, Carnegie Mellon University, Pittsburgh, Pennsylvania 15213, United States

$\S$ Department of Biomedical Engineering, Carnegie Mellon University, Pittsburgh, Pennsylvania 15213, United States

*corresponding authors (Tzahi Cohen-Karni: tzahi@andrew.cmu.edu; Benjamin M. Hunt:

bmhunt@andrew.cmu.edu) 


\section{Materials and Methods}

\section{Nanowire synthesis.}

Si nanowires (SiNWs) were synthesized through Au nanoparticle (AuNP) catalyzed vapor-liquidsolid (VLS) growth process. A $2.0 \mathrm{~cm}$ x $2.0 \mathrm{~cm}$ (100) Si substrate with a $600 \mathrm{~nm}$ wet thermal oxide (p-type, $\leq 0.005 \Omega \mathrm{cm}$, Nova Electronic Materials Ltd., catalog no. CP02 11208-OX) was cleaned with acetone and isopropyl alcohol (IPA) in an ultrasonic bath for 5 min each; and then $\mathrm{N}_{2}$ blowdried. The substrate was then placed in a UV ozone system (PSD Pro series digital UV-Ozone, Novascan) at $150{ }^{\circ} \mathrm{C}$ for $10 \mathrm{~min}$. Cleaned substrates were then functionalized with $500 \mu \mathrm{L}$ of 4:1 deionized (DI) water:poly-L-lysine (PLL) (0.1\% w/v, Sigma-Aldrich, catalog no. P8920) for 8 min. They were then gently cleaned three times in DI water and $\mathrm{N}_{2}$ blow-dried. $500 \mu \mathrm{L}$ of 9:1 DI water:30 nm AuNP solution (Ted Pella, Inc., catalog no. 15706-1) was dispersed onto the PLL coated substrate for $8 \mathrm{~min}$. The substrate was then gently washed three times in DI-water and $\mathrm{N}_{2}$ blow-dried. AuNP functionalized substrates were then introduced into a custom-built chemical vapor deposition (CVD) setup. Once a baseline pressure of $1 * 10^{-5}$ Torr was reached, the temperature was ramped up to $450{ }^{\circ} \mathrm{C}$ in $8 \mathrm{~min}$, which was followed by a 5 min temperature stabilization step. Nucleation was conducted at $450{ }^{\circ} \mathrm{C}$ for 15 min under 80 standard cubic centimeters per minute ( $\mathrm{sccm}$ ) $\mathrm{H}_{2}$ (Matheson Gas) and $20 \mathrm{sccm} \mathrm{SiH} 4$ (10\% in $\mathrm{H}_{2}$, Matheson Gas) at 40 Torr. The synthesis step was performed at $450{ }^{\circ} \mathrm{C}$ for $100 \mathrm{~min}$ under $80 \mathrm{sccm} \mathrm{H}_{2}$ and $20 \mathrm{sccm}$ $\mathrm{SiH}_{4}$ at 40 Torr. The sample was cooled down to room temperature at base pressure post-synthesis.

\section{NT-3DFG synthesis.}

3DFG was synthesized through plasma enhanced chemical vapor deposition (PECVD) process. A SiNWs sample was taken out of the NWs CVD and immediately introduced into a custom-built PECVD setup. The synthesis process was carried out at varying synthesis temperatures $\left(700{ }^{\circ} \mathrm{C}\right.$ and $1100{ }^{\circ} \mathrm{C}$, namely Conditions $\mathrm{A}$ and $\mathrm{B}$, respectively) and at a total pressure of 0.5 Torr. The SiNWs sample was placed $4.0 \mathrm{~cm}$ from the edge of the RF coil and out of the PECVD furnace. The temperature of the furnace was ramped up to the synthesis temperature at $55^{\circ} \mathrm{C} \mathrm{min}{ }^{-1}$, which was followed by a temperature stabilization step at the synthesis temperature for $5 \mathrm{~min}$, under a flow of $100 \mathrm{sccm}$ Ar (Matheson Gas). Prior to the synthesis step, inductively coupled plasma (ICP) was generated using a $13.56 \mathrm{MHz}$ RF power supply (AG 0313 Generator and AIT-600 RF, power supply and auto tuner, respectively, T\&C Power Conversion, Inc.) with the plasma power constant at $50 \mathrm{~W}$; and the furnace was moved over the sample following plasma ignition. The synthesis step was conducted under $50 \mathrm{sccm} \mathrm{CH}_{4}$ precursor $\left(5 \% \mathrm{CH}_{4}\right.$ in $\mathrm{Ar}$, Airgas) for $10 \mathrm{~min}$. The plasma was turned off after the synthesis step and the sample was rapidly cooled from growth temperature to $80{ }^{\circ} \mathrm{C}$ in $30 \mathrm{~min}$ under $100 \mathrm{sccm}$ Ar flow.

\section{NT-3DFG suspension.}

A $5 \mathrm{~mm} \times 5 \mathrm{~mm}$ sample of NT-3DFG was cleaved from the center of the sample and placed in a $2 \mathrm{~mL}$ clean glass vial (the glass vial was cleaned by ultrasonicating in acetone and IPA for $5 \mathrm{~min}$ each and $\mathrm{N}_{2}$ blow-drying). $80 \mu \mathrm{L}$ of IPA was then added to the vial. The vial was placed in an ultrasonic bath at low power for $2 \mathrm{~s}$. The suspension was then analyzed for consistency by dropcasting $5 \mu \mathrm{L}$ of suspension onto a clean $\mathrm{Si} / 600 \mathrm{~nm} \mathrm{SiO}_{2}$ wafer. IPA in the drop-casted suspension was allowed to dry. The sample was then analyzed under bright-field (BF) and dark-field (DF) using an upright optical microscope (Eclipse FN1, Nikon). 


\section{Scanning electron microscopy (SEM) imaging.}

SEM imaging was performed using a FEI Quanta 600 field emission gun (FEG) SEM. Images were acquired at accelerating voltages of $5-20 \mathrm{kV}$ with a working distance of $5 \mathrm{~mm}$. No additional conductive coating was applied to the samples to assist with imaging.

NT-3DFG diameter was evaluated using high-resolution (2048 x 1768 pixels) SEM images and ImageJ.

\section{Transmission electron microscope (TEM) imaging.}

TEM imaging was performed using a FEI Titan G2 80-300 Cs corrected TEM/STEM fitted with a high resolution Gatan Imaging Filter (GIF) Tridiem energy-filter. A lacey carbon, 300 mesh $\mathrm{Cu}$ TEM grid (Ted Pella, Inc.) was gently rubbed over a NT-3DFG sample. High-resolution TEM (HR-TEM) and selected area electron diffraction (SAED) images were acquired at an accelerating voltage of $300 \mathrm{kV}$ with 2048 x 2048 slow-scan CCD cameras. High angle annular dark field scanning transmission electron microscopy (HAADF-STEM) was performed at an accelerating voltage of $300 \mathrm{kV}$. Electron energy loss spectroscopy (EELS) was performed with a step voltage of $0.2 \mathrm{eV}$ using a high-resolution GIF Tridiem energy-filter.

SAED plane spacing analysis and fringe intensity cross-section profiles were generated from corresponding HR-TEM images with the use of ImageJ.

\section{Electron energy loss spectroscopy (EELS) simulation}

The theoretical EELS spectra were simulated using ab-initio real space full multiple scattering Green's function techniques as implemented in FEFF9 program. ${ }^{1,2}$ To describes the atomic background and the energy loss near edge fine structure we consider Hedin-Lundqvist self-energy model for the exchange and correlation potential. The core states are treated with RPA-screened core-hole during self-consistent filed (SCF) calculations. The full multiple scattering Green's function was calculated with a cluster radius large enough to specify about 50 atoms within the sphere. Calculations assumed a $300 \mathrm{keV}$ electron beam hitting the sample and the cross section is integrated over the detector aperture using a $10 \times 10 \times 1$ q-grid. An instrumental broadening of 0.5 $\mathrm{eV}$ is introduced as the imaginary energy shift of the Green's function. For various structure models, the DFT optimized structures were used in the calculations.

\section{Raman Spectroscopy.}

Raman spectroscopy was performed using NT-MDT NTEGRA Spectra with 532 and $633 \mathrm{~nm}$ excitations through a 100x objective for single and dual laser Raman analysis, respectively. Briefly, $10 \mu \mathrm{L}$ NT-3DFG suspension was drop casted onto a bond pad array and BF optical images were acquired. Raman spectra from individual NT-3DFG nanowires were then acquired with 0.5 $\mathrm{ND}$ filter and an acquisition time of $30 \mathrm{~s}$. For $\mathrm{G}$ dispersion $(\operatorname{Disp}(G))$ calculations, Raman spectra from the same point on individual nanowires were acquired using dual lasers- 532 and $633 \mathrm{~nm}$. $\operatorname{Disp}(G)$ was calculated by

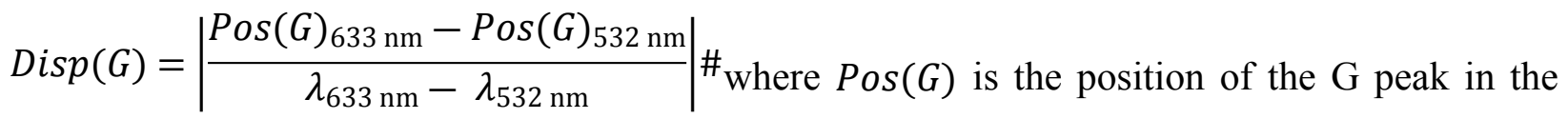
spectra acquired with a specific excitation laser and $\lambda$ is the wavelength of the excitation laser. ${ }^{3}$

Raman spectra were acquired from 30 randomly selected individual nanowires across multiple independently synthesized NT-3DFG samples $(\mathrm{n}=3)$ per synthesis condition. 


\section{Single NT-3DFG device fabrication.}

Bond pad arrays for single NT-3DFG devices were fabricated on a 3" (100) Si wafer with a 600 $\mathrm{nm}$ wet thermal oxide (p-type, $\leq 0.005 \Omega \mathrm{cm}$, Nova Electronic Materials Ltd., catalog no. CP02 11208-OX) using photolithography and thermal evaporation techniques. Briefly, the substrate wafer was cleaned with acetone and IPA in an ultrasonic bath for 5 min each; and $\mathrm{N}_{2}$ blow-dried. $300 \mathrm{~nm}$ LOR3A (MicroChem) was coated onto the substrate and baked at $190{ }^{\circ} \mathrm{C}$ for $5 \mathrm{~min}$. This was followed by coating $500 \mathrm{~nm}$ Shipley 1805 Photoresist (MicroChem) onto the LOR3A coated substrate and baking at $115^{\circ} \mathrm{C}$ for $5 \mathrm{~min}$. A custom designed mask was used to pattern the resist by UV exposure using a mask aligner (MA6, SUSS MicroTec). The pattern was developed using a Microposit MF CD-26 developer (MicroChem) for $48 \mathrm{~s}$. The patterned substrate was then cleaned three times with DI water. Bond pads composed of $5 \mathrm{~nm} \mathrm{Cr}$ (99.99 \%, R.D. Mathis Co.) and $150 \mathrm{~nm} \mathrm{Au}(99.999 \%$, Praxair) were then evaporated onto the patterned substrate using a thermal evaporator (Covap II, Angstrom Engineering Inc.). Post metal deposition, the LOR3A/Shipley 1805/Cr/Au stack was stripped off using Remover PG (MicroChem). The prepared bond pad arrays were cleaned with acetone and IPA; and then $\mathrm{N}_{2}$ blow-dried.

Single NT-3DFG devices were fabricated using electron-beam (e-beam) lithography. Briefly, 10 $\mu \mathrm{L}$ of desired NT-3DFG nanowire suspension was drop-casted $2 \mu \mathrm{L}$ at a time onto a $5 \mathrm{~mm} \times 10$ $\mathrm{mm}$ bond pad array chip. After IPA in the drop-casted NT-3DFG suspension had evaporated, the density of drop-casted nanowires was checked through BF/DF optical microscopy. To perform ebeam lithography, methyl methacrylate (MMA) (MMA EL 13, MicroChem) was spin-coated at $2000 \mathrm{rpm}$ for $90 \mathrm{~s}$ onto the chips as a lift-off resist. The MMA coated chips were then baked at $175^{\circ} \mathrm{C}$ for $90 \mathrm{~s}$ and cooled down to room temperature for $5 \mathrm{~min}$. This was followed by spin-coating poly (methyl methacrylate) (PMMA) (950 PMMA A4, MicroChem) at $3000 \mathrm{rpm}$ for $90 \mathrm{~s}$ onto the MMA coated chips as an e-beam resist. The PMMA coated chips were then baked at $175{ }^{\circ} \mathrm{C}$ for $15 \mathrm{~min}$ and cooled down to room temperature for $5 \mathrm{~min}$. BF images were acquired at magnifications 5, 20 and 50x for e-beam pattern designing using an upright optical microscope (Eclipse LV100ND, Nikon).

E-beam patterns were designed using DesignCAD 21 and NPGS. Designed e-beam patterns were written on bond pad arrays of interest using NPGS on a Sirion 600 scanning electron microscope with an accelerating voltage of $30 \mathrm{kV}$, working distance of $5 \mathrm{~mm}$ and a spot size of 3 . The pattern was then developed using cold 3:1 (w/w) IPA:DI water for 2 min, approximately. Ohmic metal contacts were then deposited using a Lesker e-beam evaporator $(5 \mathrm{~nm} \mathrm{Cr} / 150 \mathrm{~nm} \mathrm{Au}$ for single NT-3DFG devices and $1.5 \mathrm{~nm} \mathrm{Cr} / 50 \mathrm{~nm} \mathrm{Pd} / 30 \mathrm{~nm}$ Au for intrinsic SiNW devices). Lift-off was performed under acetone at $52{ }^{\circ} \mathrm{C}$ for $30 \mathrm{~min}$ and was followed by IPA wash and gentle $\mathrm{N}_{2}$ blowdry. Device chips were then loaded onto 16-pin carriers using fast drying Ag-paint (Ted Pella, Inc.) and wire bonded with $\mathrm{Au}$ wire using a manual wedge wire bonder (West Bond, Inc.). The devices were then checked for functional contacts by supplying $85 \mathrm{nA}$ through Keithley 2400 (1 $\mathrm{V}$ DC through $11.82 \mathrm{k} \Omega$ ). NT-3DFG nanowires retain their respective morphologies post device fabrication, as observed through SEM imaging and Raman spectroscopy (Figure S6.b and c).

\section{Electron transport measurements.}

Functional NT-3DFG devices were loaded into a Physical Properties Measurement System (PPMS, Model 6000, Quantum Design) fitted with a magnet controller (Model 6700, Quantum Design). Current bias measurement scheme was followed for all electrical measurements. $100 \mathrm{nA}$ alternating current $(\mathrm{AC})$ was supplied through the device by applying an external potential of $1 \mathrm{~V}$ 
(frequency $\sim 13$ to $37 \mathrm{~Hz}$, with low phase) using a SR860 $500 \mathrm{kHz}$ DSP lock-in amplifier (Stanford Research Systems) through an external $10 \mathrm{M} \Omega$ resistor. The current was supplied through the source contact and the current was measured using the same lock-in at the drain contact. Fourterminal measurements were performed using a separate SR860 $500 \mathrm{kHz}$ DSP lock-in amplifier by measuring the potential drop and the current following across contact leads in between the source and the drain.

Four-terminal resistance as a function of device temperature $(2$ to $300 \mathrm{~K})$ was measured at $0 \mathrm{~T}$ magnetic field (perpendicular to the plane of the device).

The VRH component of the measured device resistance was calculated by

$$
R_{\text {measured VRH }}=R_{0} R(\mathrm{~T}) /\left(R_{0}-R(\mathrm{~T})\right) \#
$$

where $R_{\text {measured VRH }}, R_{0}$ and $R(\mathrm{~T})$ are the VRH component of the measured resistance, temperature independent component of resistance and measured device resistance as a function of temperature, respectively.

\section{Resistivity calculations.}

The resistivity of the graphitic shell $(\rho)$ was calculated following the equation,

$$
\begin{gathered}
\rho=R_{0} * \frac{A}{l} \\
A=\pi *\left((r+t)^{2}-r^{2}\right)
\end{gathered}
$$

where $R_{0}, A, l, r$ and $t$ are the determined graphitic shell resistance, area of the graphitic shell, length of the device, radius of the i-SiNW core and thickness of the graphitic shell, respectively. The thickness of the graphitic shell for NT-3DFG synthesized under Conditions A and B was ca. 5 and $60 \mathrm{~nm}$, respectively (as determined from STEM images and EELS spectra, Fig. 2). The radius of the i-SiNW core is approximated as $30 \mathrm{~nm}$ since $30 \mathrm{~nm}$ AuNP catalysts were used for iSiNW synthesis. For all devices, the calculated resistivity of the graphitic shell (Table S7) agrees with that reported for graphitic structures. ${ }^{4}$

\section{Magnetoresistance measurements.}

Magnetoresistance (MR) measurements were performed on the same single NT-3DFG devices on which electron transport measurements were performed. Four-terminal resistance was measured in a current bias scheme in which $100 \mathrm{nA}$ alternating current (AC) was supplied through the device by applying an external potential of $1 \mathrm{~V}$ (frequency $\sim 13$ to $37 \mathrm{~Hz}$, with low phase) using a SR860 $500 \mathrm{kHz}$ DSP lock-in amplifier (Stanford Research Systems) through an external $10 \mathrm{M} \Omega$ resistor. The potential drop across contact leads between the source and the drain was measured using a separate SR860 $500 \mathrm{kHz}$ DSP lock-in amplifier.

Resistance was measured as a function a magnetic field by sweeping the magnetic field from $-9 \mathrm{~T}$ to $+9 \mathrm{~T}$ (perpendicular to the plane of the device) at different device temperatures $(2,4,6,8,20$, $50,200$ and $300 \mathrm{~K})$. MR was calculated following the equation,

$$
M R=(R(\mathrm{~B})-R(0 \mathrm{~T})) / R(0 \mathrm{~T}) \#
$$

where $R(\mathrm{~B})$ and $R(0 \mathrm{~T})$ are the measured four-terminal resistances as a function of magnetic field and at $0 \mathrm{~T}$ magnetic field, respectively. 


\section{Additional Notes}

\section{$X$-ray photoelectron spectroscopy of NT-3DFG.}

We observe a prominent $\mathrm{sp}^{2}$ hybridized carbon $1 \mathrm{~s}(\mathrm{C} 1 \mathrm{~s})$ peak at 284.14 and $284.25 \mathrm{eV}$ for Condition A and B, respectively (Figure S2.a, b.I and c.I). This corroborates the presence of the $\mathrm{sp}^{2} \mathrm{C}$ lattice of graphene. ${ }^{5,6}$ The $\pi \rightarrow \pi^{*}$ shake up satellite peak is also observed at 290.02 and $290.29 \mathrm{eV}$ for Conditions A and B, respectively. Absence of the Si peak (Si2p) from spectra for both conditions (Figure S2.b.II and c.II) indicates that the i-SiNWs are conformally coated by carbon. The low intensity O1s peak observed in the case of Condition A (Figure S2.b.III) is attributed to environmental contamination by organic species with $\mathrm{C}-\mathrm{O}$ bonds. $^{7}$

\section{Raman spectroscopy of NT-3DFG.}

The emergence of the characteristic Raman peaks, i.e., D, G, D' and 2D peaks (Figure S3.a and Table S1) shows the presence of graphene in NT-3DFG synthesized under both Conditions A and $\mathrm{B} .{ }^{8}$ We observe that the $\mathrm{I}_{\mathrm{D}} / \mathrm{I}_{\mathrm{G}}$ ratio decreases with increasing synthesis temperature, suggesting an increase in the graphene crystallite size (Figure S3.b and Table S2). ${ }^{9-11}$ On the other hand, the $\mathrm{I}_{2 \mathrm{D}} / \mathrm{I}_{\mathrm{G}}$ ratio increases with increasing synthesis temperature (Figure S3.b and Table S2), indicating an increase in NT-3DFG edge density. ${ }^{3,} 12$ These observations are consistent with our electron microscopy results. Both D and D' Raman peaks require breaks in translation symmetry in the graphene lattice for activation, indicating the presence of defects. ${ }^{8}$ The emergence of the these peaks suggests the presence of high density of defects in the NT-3DFG structure. With increasing disorder in carbon structure, an increase in the position of the $G$ peak as a function of excitation wavelength $(\operatorname{Disp}(\mathrm{G}))$ as well as the full width at half maximum of the $G$ peak (FWHM(G)) is expected. ${ }^{13}$ Absence of clear correlations between $\mathrm{I}_{\mathrm{D}} / \mathrm{I}_{\mathrm{G}}$ and $\operatorname{Disp}(\mathrm{G})$, and $\mathrm{I}_{\mathrm{D}} / \mathrm{I}_{\mathrm{G}}$ and $\mathrm{FWHM}(\mathrm{G})$ suggest absence of bulk structural defects (Figure S3.c and d). ${ }^{3,13-15}$ Therefore, the strong D peak is primarily due to the presence of edge defects in the free-standing graphene lattice.

\section{High resolution transmission electron microscopy (HR-TEM) of NT-3DFG.}

Templated fuzzy graphene is composed of single- to -few-layer free-stranding graphene flakes (Figure S4.a.I and b.I). The interplanar fringe intensities for Conditions A and B are calculated to be 0.35 and $0.36 \mathrm{~nm}$, respectively, indicating the presence of turbostratic graphene in both conditions (insets, Figure S4.a.II and b.II). The presence of diffraction rings in selected area electron diffraction (SAED) patterns (Figure S4.a.III and b.III) reveals the polycrystalline structure of NT-3DFG synthesized under both conditions. ${ }^{16}$ The experimentally determined

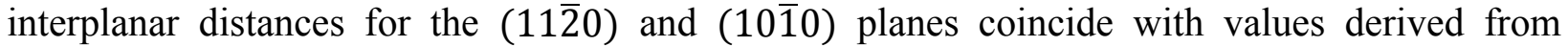
literature (Table S5). ${ }^{17,} 18$ However, the interplanar distance across the (0002) plane is greater than the expected value of $0.344 \mathrm{~nm}$, indicating the presence of turbostratic graphene. ${ }^{19-21}$ Thus, the polycrystalline network of flakes is mostly composed of $\mathrm{sp}^{2}$ carbon with exposed-edge single- to few-layer free-standing graphene. 


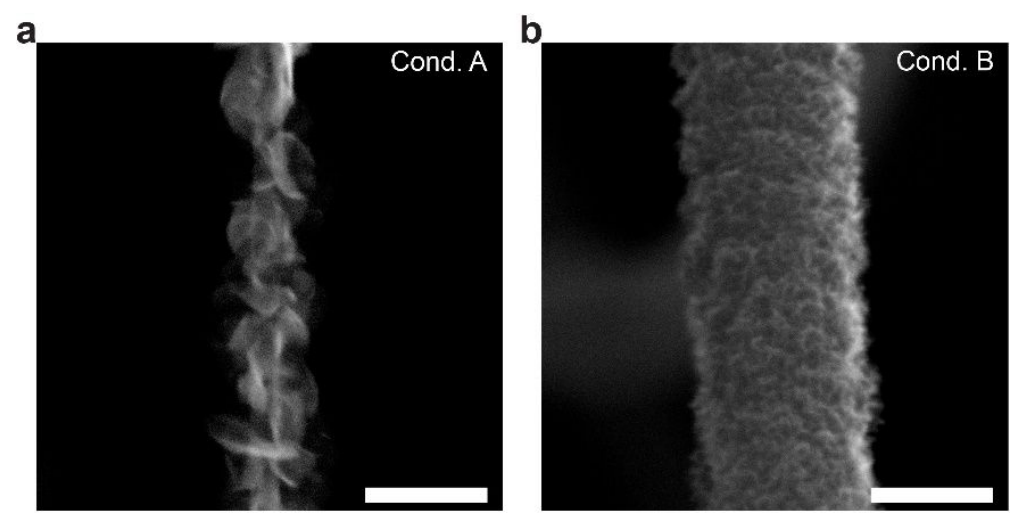

Figure S1. SEM of NT-3DFG. Representative SEM image of NT-3DFG synthesized under (a) Condition A and (b) Condition B. Scale bars are $200 \mathrm{~nm}$. 


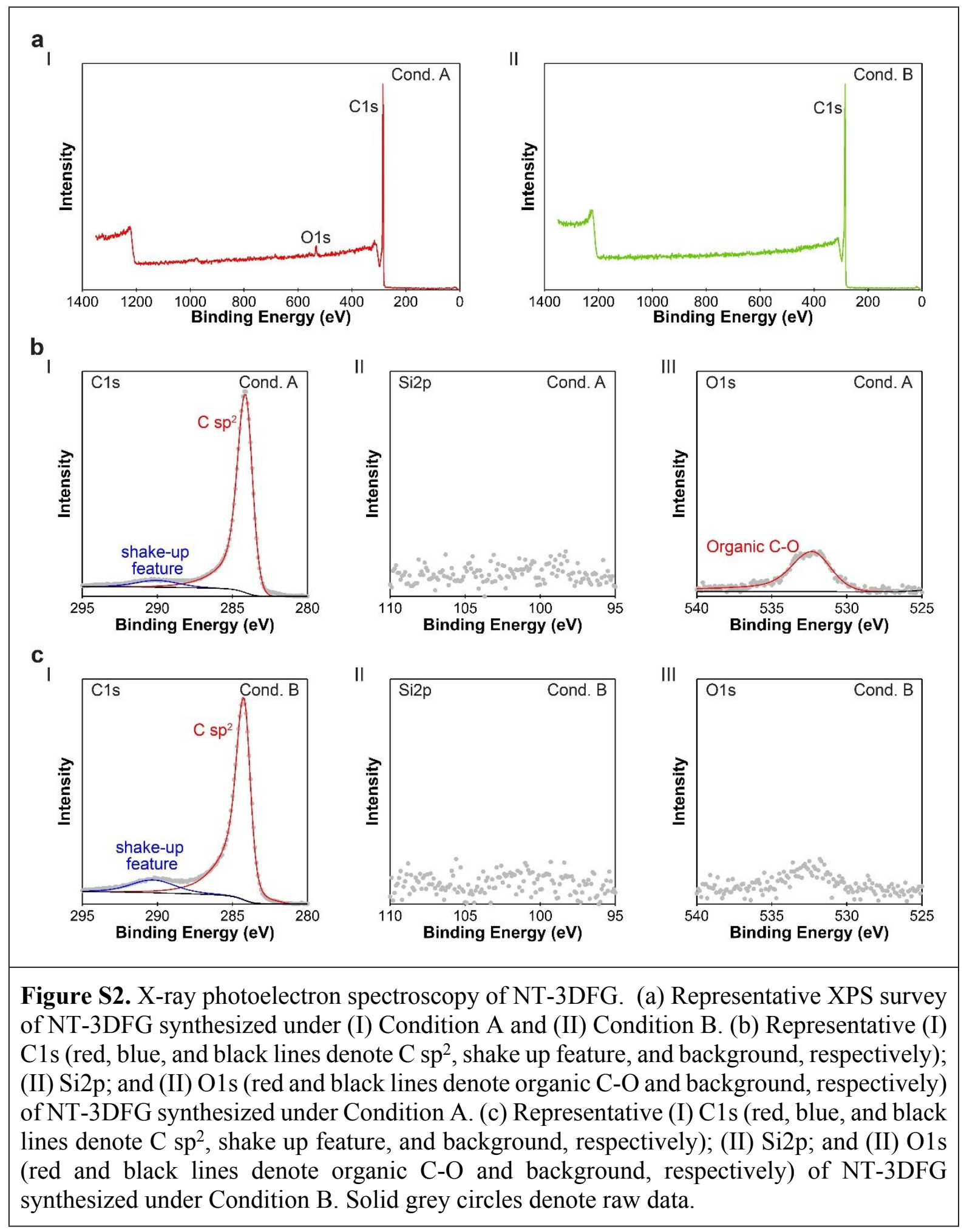


a

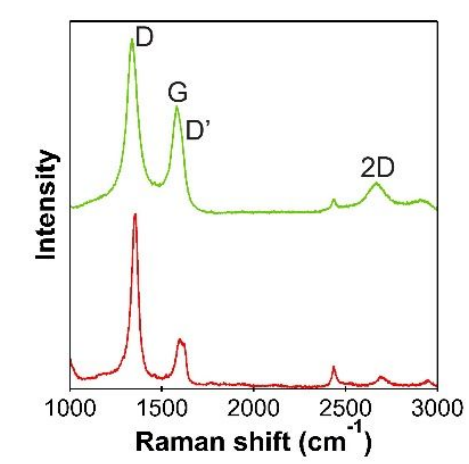

C
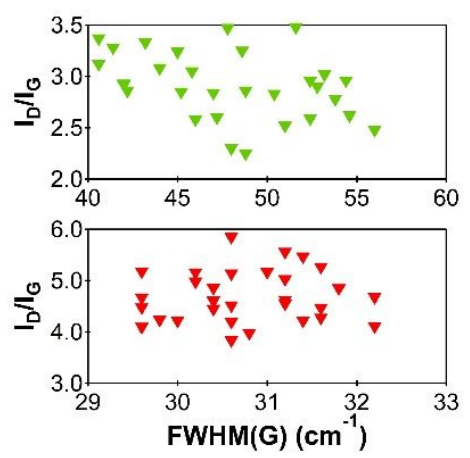

b

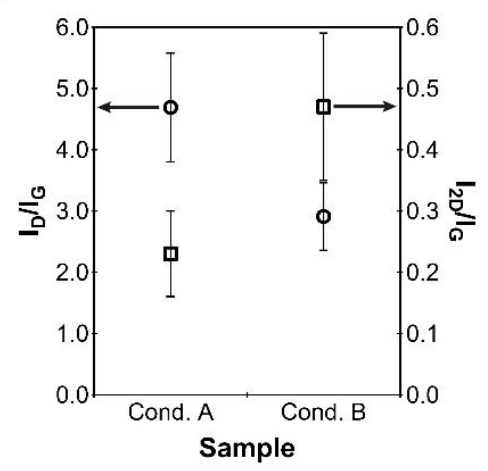

d
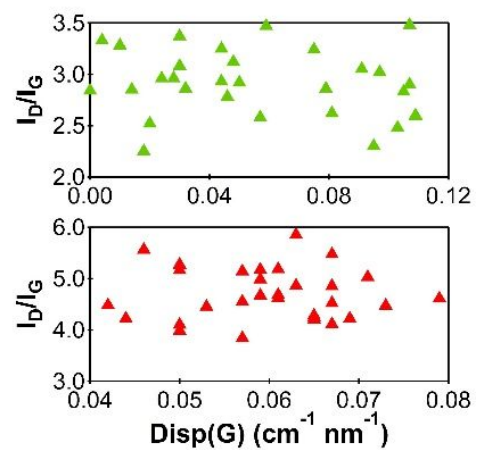

Figure S3. Raman spectroscopy of NT-3DFG. (a) Representative Raman spectra of single NT-3DFG nanowires. (b) Peak intensity ratio of $\mathrm{D}$ peak to $\mathrm{G}$ peak $\left(\mathrm{I}_{\mathrm{D}} / \mathrm{I}_{\mathrm{G}}\right.$ represented by open circles) and $2 \mathrm{D}$ peak to $\mathrm{G}$ peak $\left(\mathrm{I}_{2 \mathrm{D}} / \mathrm{I}_{\mathrm{G}}\right.$ represented by open squares) for single NT-3DFG nanowires. Data is presented as mean \pm standard deviation. Peak intensity ratio of $D$ peak to G peak $\left(\mathrm{I}_{\mathrm{D}} / \mathrm{I}_{\mathrm{G}}\right)$ as a function of (c) FWHM of G peak; and (d) dispersion of $\mathrm{G}$ peak for single NT-3DFG nanowires. Red and green represent NT-3DFG synthesized under Conditions A and $\mathrm{B}$, respectively. 


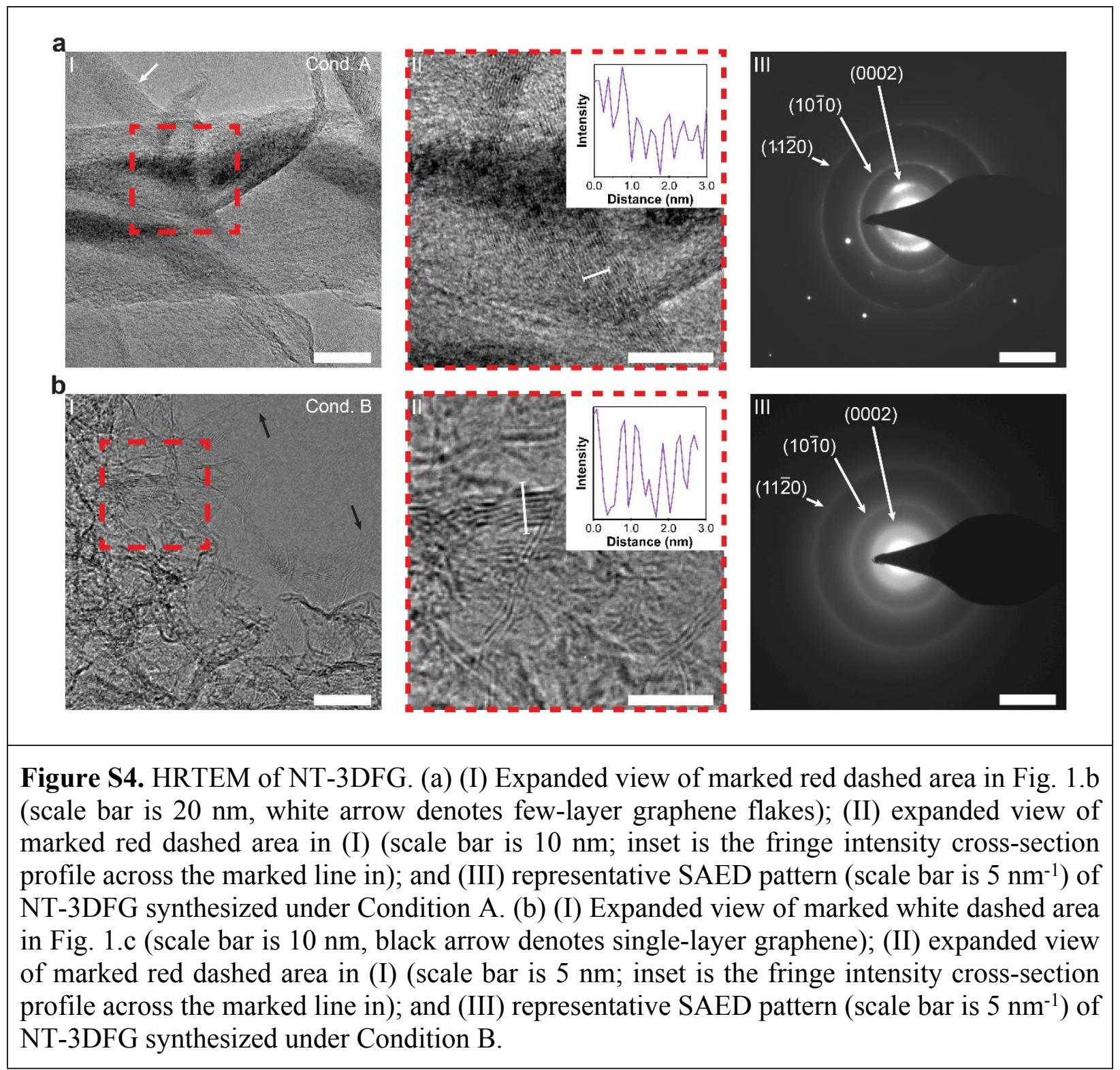


a

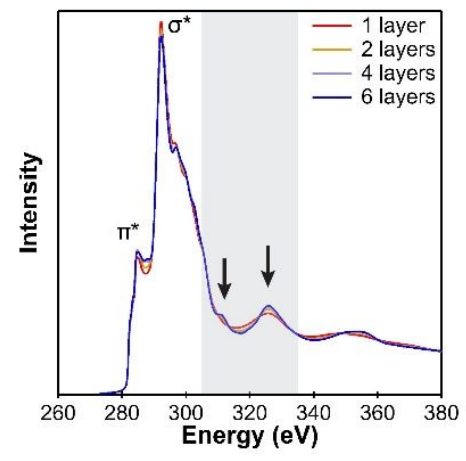

b

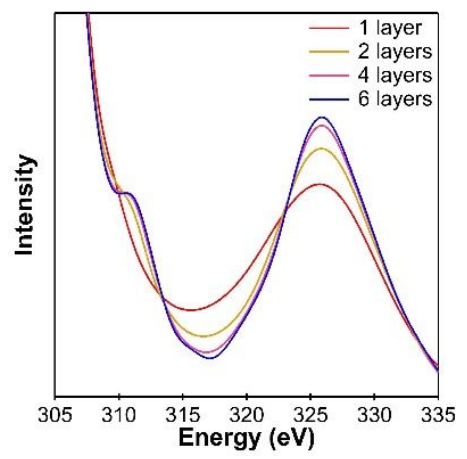

Figure S5. Simulation of EELS spectra. (a) Simulated EELS spectra of graphene with 1, 2,4, and 6 layers. Gray region denotes extended fine features in respective EELS spectra. Black arrows denote interference peaks due to multiple scattering events. (b) Expanded view of the gray region in (a). 


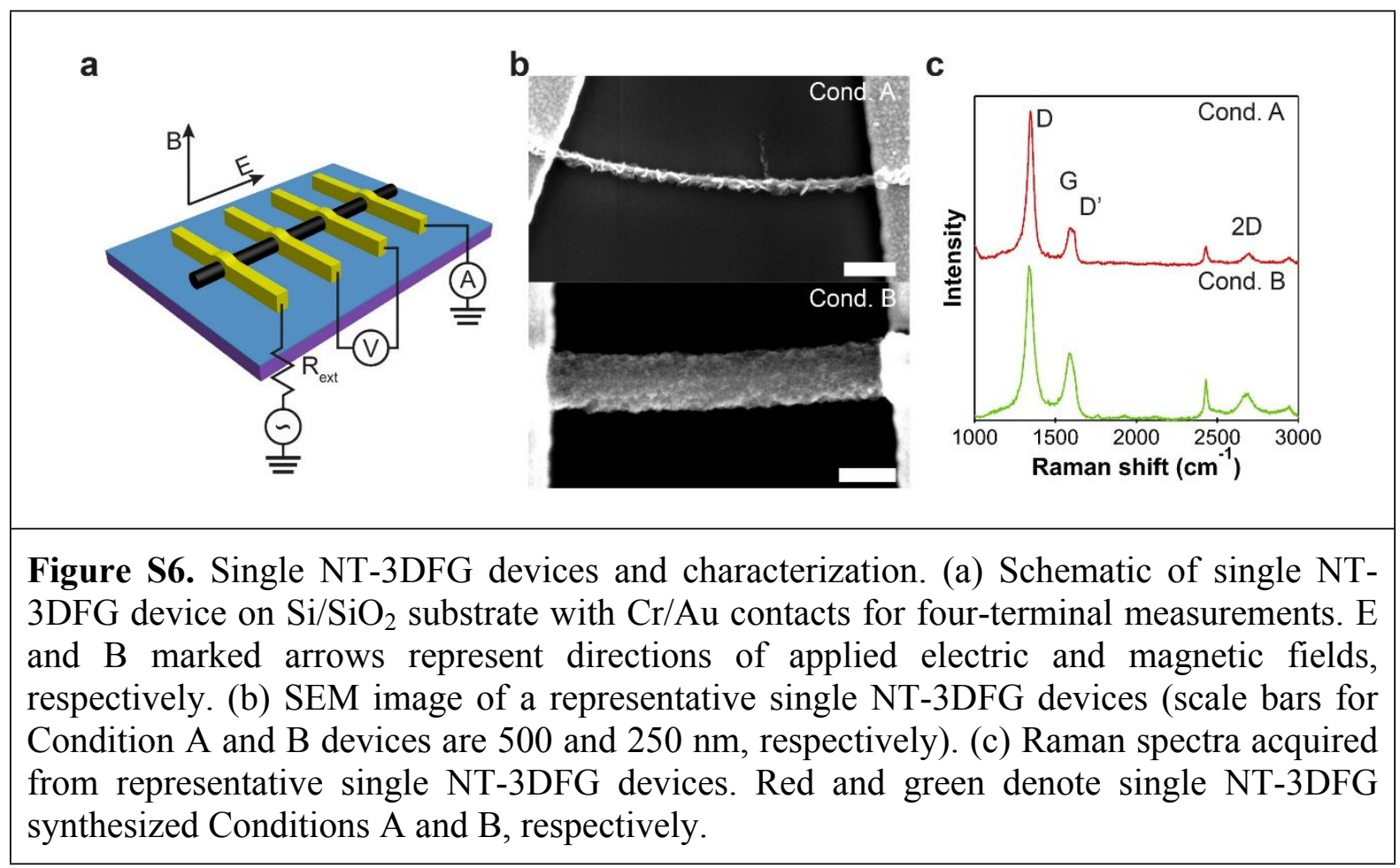



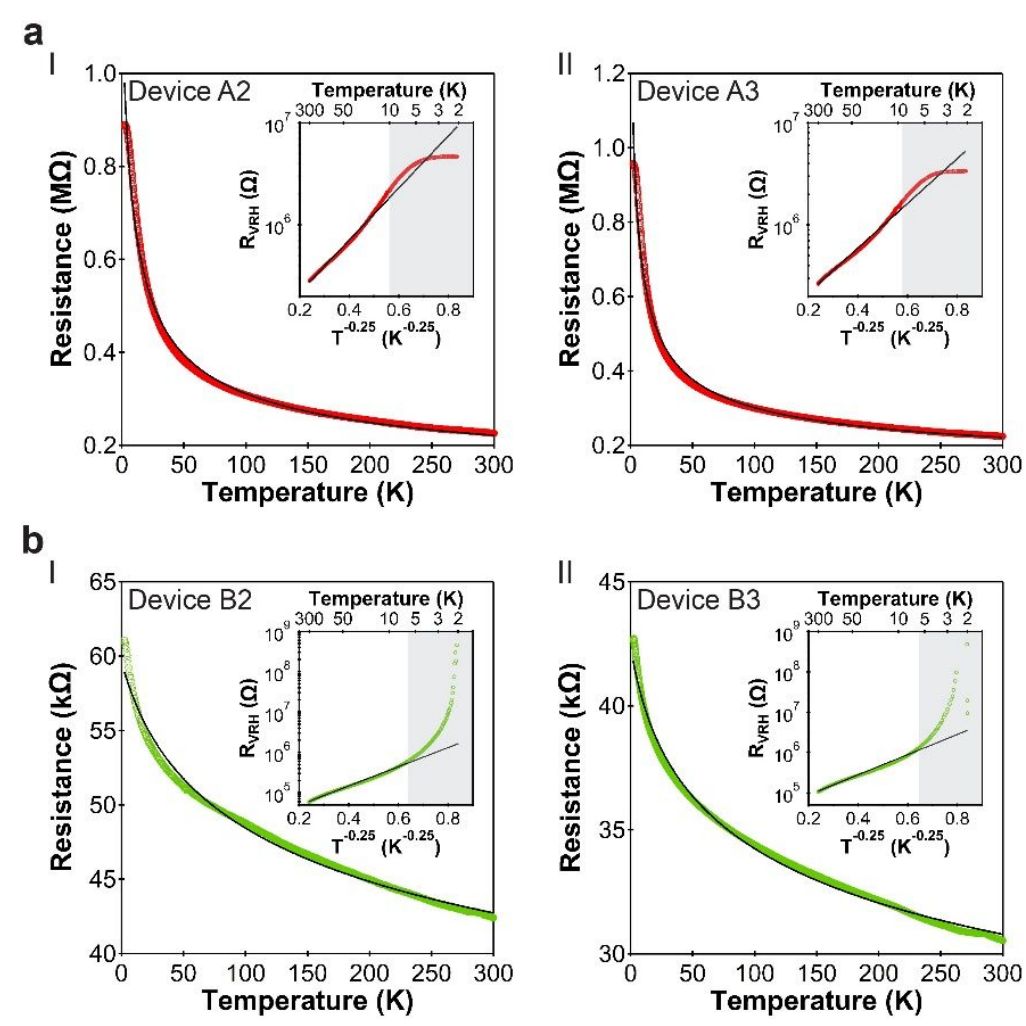

Figure S7. Electrical characterization of single NT-3DFG. Resistance as a function of temperature acquired from single NT-3DFG devices (a) A2 (I) and A3 (II), and (b) B2 (I) and B3 (II). Empty circles and solid black lines denote experimental data and parallel resistance electron transport model fit, respectively. Insets present VRH component of the measured fourterminal resistance (empty circles) and theoretical VRH resistance determined from the parallel resistance model (black solid line) as a function of $\mathrm{T}^{-0.25}$ (gray regions denote deviation from proposed model at low temperatures). 

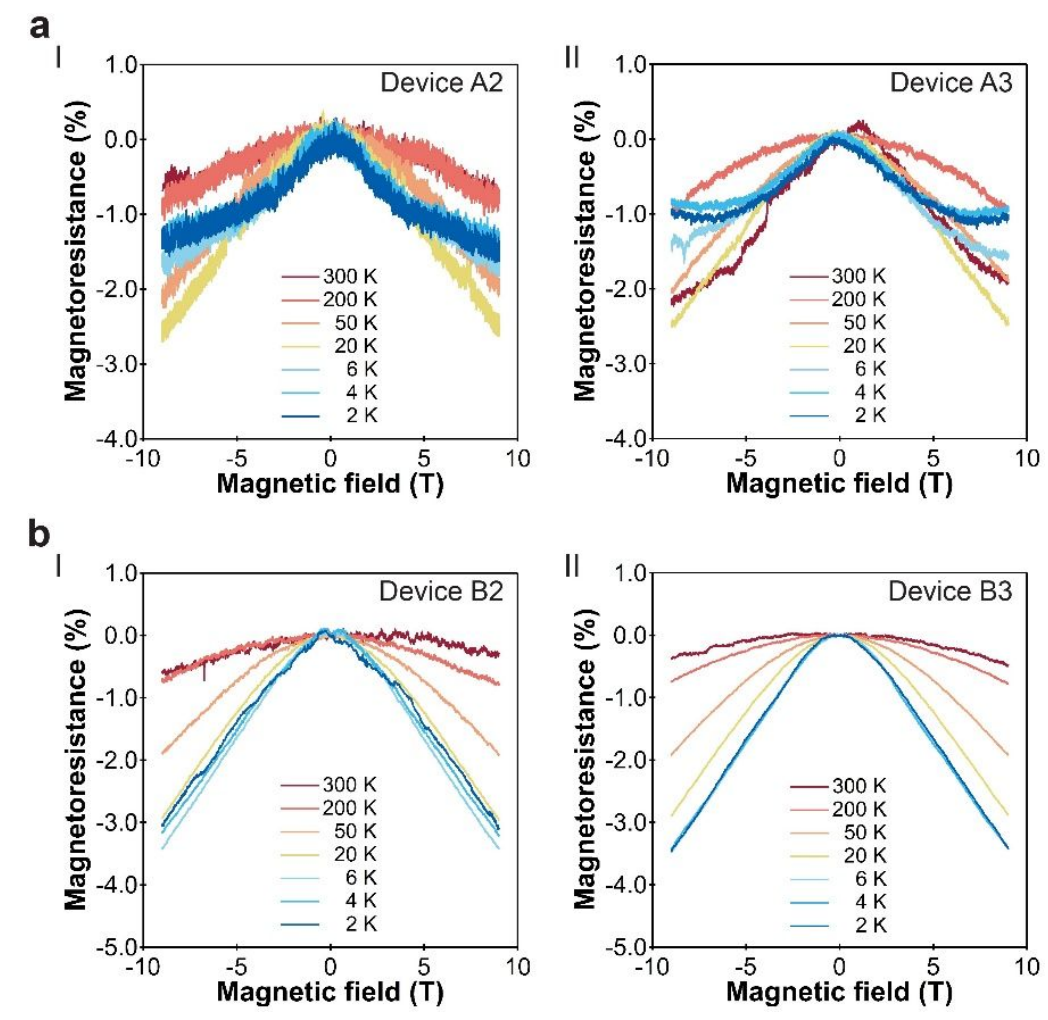

Figure S8. Magnetoresistance characterization of single NT-3DFG. Magnetoresistance as a function of applied perpendicular magnetic field acquired from single NT-3DFG devices (a) A2 (I) and A3 (II), and (b) B2 (I) and B3 (II). 
Table S1. Data summary of Raman analysis of NT-3DFG synthesized at varying temperatures (Supplementary Figure 3.a).

\begin{tabular}{|c|c|c|c|c|c|c|c|}
\hline Sample & $\begin{array}{c}\text { Position(D) } \\
\left(\mathrm{cm}^{-1}\right)\end{array}$ & $\begin{array}{c}\operatorname{Position}(G) \\
\left(\mathrm{cm}^{-1}\right)\end{array}$ & $\begin{array}{c}\text { Position(D') } \\
\left(\mathrm{cm}^{-1}\right)\end{array}$ & $\begin{array}{c}\operatorname{Position}(2 \mathrm{D}) \\
\left(\mathrm{cm}^{-1}\right)\end{array}$ & $\begin{array}{c}\text { FWHM(D) } \\
\left(\mathrm{cm}^{-1}\right)\end{array}$ & $\begin{array}{c}\text { FWHM(G) } \\
\left(\mathrm{cm}^{-1}\right)\end{array}$ & $\begin{array}{c}\text { FWHM(2D) } \\
\left(\mathrm{cm}^{-1}\right)\end{array}$ \\
\hline $\begin{array}{c}\text { Cond. } \\
\text { A }\end{array}$ & $\begin{array}{c}1352.0 \\
\pm 1.2\end{array}$ & $\begin{array}{c}1591.8 \\
\pm 1.8\end{array}$ & $\begin{array}{c}1617.2 \\
\pm 1.4\end{array}$ & $\begin{array}{c}2697.4 \\
\pm 3.0\end{array}$ & $44.2 \pm 2.6$ & $30.8 \pm 1.4$ & $52.2 \pm 16.8$ \\
\hline $\begin{array}{c}\text { Cond. } \\
\text { B }\end{array}$ & $\begin{array}{c}1343.6 \\
\pm 6.0\end{array}$ & $\begin{array}{c}1579.6 \\
\pm 8.6\end{array}$ & $\begin{array}{c}1605.6 \\
\pm 9.4\end{array}$ & $\begin{array}{l}2679.6 \\
\pm 11.6\end{array}$ & $59.4 \pm 5.0$ & $48.0 \pm 5.6$ & $92.2 \pm 10.0$ \\
\hline
\end{tabular}


Table S2. Data summary of Raman analysis of NT-3DFG synthesized at varying temperatures (Supplementary Figure 3.b).

\begin{tabular}{|c|c|c|}
\hline Sample & $\mathbf{I}_{\mathbf{D}} / \mathbf{I}_{\mathbf{G}}$ & $\mathbf{I}_{\mathbf{2}} / \mathbf{I}_{\mathbf{G}}$ \\
\hline Cond. A & $4.69 \pm 0.89$ & $0.23 \pm 0.07$ \\
\hline Cond. B & $2.91 \pm 0.55$ & $0.47 \pm 0.12$ \\
\hline
\end{tabular}


Table S3. Data summary of dual laser Raman analysis of NT-3DFG synthesized under Condition A (Supplementary Figure 3.c and d).

\begin{tabular}{|c|c|c|c|c|}
\hline Sample & Region & $\mathbf{I}_{\mathbf{D}} / \mathbf{I}_{\mathbf{G}}$ & $\begin{array}{c}\text { FWHM(G) } \\
\left(\mathrm{cm}^{-1}\right)\end{array}$ & $\begin{array}{c}\operatorname{Disp}(G) \\
\left(\mathrm{cm}^{-1} \mathbf{n m}^{-1}\right)\end{array}$ \\
\hline \multirow{10}{*}{$\mathbf{N}=\mathbf{1}$} & 1 & 4.45 & 30.4 & 0.05 \\
\hline & 2 & 4.11 & 32.2 & 0.07 \\
\hline & 3 & 5.17 & 31.0 & 0.06 \\
\hline & 4 & 3.84 & 30.6 & 0.06 \\
\hline & 5 & 5.47 & 31.4 & 0.07 \\
\hline & 6 & 4.47 & 31.6 & 0.07 \\
\hline & 7 & 4.98 & 30.2 & 0.06 \\
\hline & 8 & 4.62 & 31.2 & 0.06 \\
\hline & 9 & 5.03 & 31.2 & 0.07 \\
\hline & 10 & 5.85 & 30.6 & 0.06 \\
\hline \multirow{10}{*}{$\mathbf{N}=\mathbf{2}$} & 1 & 4.85 & 31.8 & 0.07 \\
\hline & 2 & 4.22 & 31.4 & 0.07 \\
\hline & 3 & 4.61 & 30.4 & 0.08 \\
\hline & 4 & 4.67 & 29.6 & 0.06 \\
\hline & 5 & 5.27 & 31.6 & 0.05 \\
\hline & 6 & 4.55 & 31.2 & 0.06 \\
\hline & 7 & 4.48 & 29.6 & 0.04 \\
\hline & 8 & 4.86 & 30.4 & 0.06 \\
\hline & 9 & 4.20 & 30.6 & 0.06 \\
\hline & 10 & 5.14 & 30.6 & 0.06 \\
\hline \multirow{10}{*}{$\mathbf{N}=\mathbf{3}$} & 1 & 4.68 & 32.2 & 0.06 \\
\hline & 2 & 4.52 & 30.6 & 0.07 \\
\hline & 3 & 3.98 & 30.8 & 0.05 \\
\hline & 4 & 4.10 & 29.6 & 0.05 \\
\hline & 5 & 5.56 & 31.2 & 0.04 \\
\hline & 6 & 4.24 & 29.8 & 0.07 \\
\hline & 7 & 4.28 & 31.6 & 0.07 \\
\hline & 8 & 4.22 & 30.0 & 0.04 \\
\hline & 9 & 5.16 & 30.2 & 0.05 \\
\hline & 10 & 5.18 & 29.6 & 0.06 \\
\hline
\end{tabular}


Table S4. Data summary of dual laser Raman analysis of NT-3DFG synthesized under Condition B (Supplementary Figure 3.c and d).

\begin{tabular}{|c|c|c|c|c|}
\hline Sample & Region & $\mathbf{I}_{\mathbf{D}} / \mathbf{I}_{\mathbf{G}}$ & $\begin{array}{c}\text { FWHM(G) } \\
\left(\mathrm{cm}^{-1}\right)\end{array}$ & $\begin{array}{c}\operatorname{Disp}(G) \\
\left(\mathrm{cm}^{-1} \mathrm{~nm}^{-1}\right)\end{array}$ \\
\hline \multirow{10}{*}{$\mathbf{N}=\mathbf{1}$} & 1 & 3.47 & 47.8 & 0.06 \\
\hline & 2 & 3.02 & 53.2 & 0.10 \\
\hline & 3 & 2.86 & 48.8 & 0.08 \\
\hline & 4 & 3.25 & 48.6 & 0.04 \\
\hline & 5 & 2.96 & 52.4 & 0.02 \\
\hline & 6 & 2.96 & 54.4 & 0.03 \\
\hline & 7 & 2.78 & 53.8 & 0.05 \\
\hline & 8 & 2.90 & 52.8 & 0.11 \\
\hline & 9 & 2.83 & 50.4 & 0.11 \\
\hline & 10 & 2.59 & 52.4 & 0.11 \\
\hline \multirow{10}{*}{$\mathbf{N}=\mathbf{2}$} & 1 & 2.60 & 47.2 & 0.11 \\
\hline & 2 & 2.52 & 51.0 & 0.02 \\
\hline & 3 & 3.48 & 51.6 & 0.11 \\
\hline & 4 & 2.25 & 48.8 & 0.02 \\
\hline & 5 & 3.37 & 40.6 & 0.03 \\
\hline & 6 & 2.62 & 54.6 & 0.08 \\
\hline & 7 & 2.30 & 48.0 & 0.09 \\
\hline & 8 & 3.05 & 45.8 & 0.09 \\
\hline & 9 & 2.48 & 56.0 & 0.10 \\
\hline & 10 & 2.85 & 45.2 & 0.01 \\
\hline \multirow{10}{*}{$\mathbf{N}=\mathbf{3}$} & 1 & 3.08 & 44.0 & 0.03 \\
\hline & 2 & 2.58 & 46.0 & 0.06 \\
\hline & 3 & 3.33 & 43.2 & 0.00 \\
\hline & 4 & 2.92 & 42.0 & 0.05 \\
\hline & 5 & 3.28 & 41.4 & 0.01 \\
\hline & 6 & 2.93 & 42.0 & 0.04 \\
\hline & 7 & 3.24 & 45.0 & 0.07 \\
\hline & 8 & 2.84 & 47.0 & 0.00 \\
\hline & 9 & 3.12 & 40.6 & 0.05 \\
\hline & 10 & 2.86 & 42.2 & 0.03 \\
\hline
\end{tabular}


Table S5. Summary of inter-planar spacing determined from SAED patterns.

\begin{tabular}{|c|c|c|c|}
\hline $\begin{array}{c}\text { C-C } \\
\text { neighbour }\end{array}$ & $\begin{array}{c}\text { Condition A } \\
\text { experimental } \\
\text { values } \\
\text { (nm) }\end{array}$ & $\begin{array}{c}\text { Condition B } \\
\text { experimental } \\
\text { values } \\
\text { (nm) }\end{array}$ & $\begin{array}{c}\text { Graphene } \\
\text { literature } \\
\text { derived } \\
\text { value (nm) }\end{array}$ \\
\hline $\begin{array}{c}\mathbf{1}^{\text {st }} \text { nearest } \\
\text { neighbour }\end{array}$ & 0.121 & 0.123 & $0.123^{17}$ \\
\hline $\begin{array}{c}\mathbf{2}^{\text {nd }} \text { nearest } \\
\text { neighbour }\end{array}$ & 0.207 & 0.213 & $0.213^{17}$ \\
\hline $\begin{array}{c}\text { Inter-layer } \\
\text { spacing }\end{array}$ & 0.357 & 0.399 & $0.340^{18}$ \\
\hline
\end{tabular}


Table S6. Data summary of electron transport model fits to experimental data for various single NT-3DFG devices fabricated with NT-3DFG synthesized at different temperatures.

\begin{tabular}{|c|c|c|c|c|c|}
\hline Sample & Device & $\boldsymbol{R}_{\mathbf{0}}$ & $R_{1}$ & $T_{0}$ & $R^{2}$ \\
\hline \multirow{3}{*}{ Cond. A } & $\begin{array}{c}\text { A1 } \\
\text { (Fig. 3.b) }\end{array}$ & $1.71 \mathrm{M} \Omega$ & $96.32 \mathrm{k} \Omega$ & $509 \mathrm{~K}$ & 0.99 \\
\hline & $\begin{array}{c}\text { A2 } \\
\text { (Figure S7.a.I) }\end{array}$ & $1.10 \mathrm{M} \Omega$ & $67.62 \mathrm{k} \Omega$ & $1193 \mathrm{~K}$ & 0.99 \\
\hline & $\begin{array}{c}\text { A3 } \\
\text { (Figure S7.a.II) }\end{array}$ & $1.34 \mathrm{M} \Omega$ & $79.07 \mathrm{k} \Omega$ & $643 \mathrm{~K}$ & 0.99 \\
\hline \multirow{3}{*}{ Cond. B } & $\begin{array}{c}\text { B1 } \\
\text { (Fig. 3.c) }\end{array}$ & $26.13 \mathrm{k} \Omega$ & $16.56 \mathrm{k} \Omega$ & $893 \mathrm{~K}$ & 0.99 \\
\hline & $\begin{array}{c}\text { B2 } \\
\text { (Figure S7.b.I) }\end{array}$ & $61.08 \mathrm{k} \Omega$ & $32.10 \mathrm{k} \Omega$ & $1511 \mathrm{~K}$ & 0.99 \\
\hline & $\begin{array}{c}\text { B3 } \\
\text { (Figure S7.b.II) }\end{array}$ & $42.71 \mathrm{k} \Omega$ & $27.69 \mathrm{k} \Omega$ & $1110 \mathrm{~K}$ & 0.99 \\
\hline
\end{tabular}


Table S7. Data summary of resistivity ( $\rho$ ) of graphitic shell as extrapolated from determined $R_{0}$ of NT-3DFG synthesized under Conditions A and B.

\begin{tabular}{|c|c|c|c|c|c|c|}
\hline Sample & Device & $\begin{array}{l}\text { Device } \\
\text { length } \\
\text { (m) }\end{array}$ & $\begin{array}{l}\text { Graphitic } \\
\text { shell } \\
\text { thickness } \\
\text { (m) }\end{array}$ & $\begin{array}{c}\text { Graphitic } \\
\text { shell area } \\
\left(\mathbf{m}^{2}\right)\end{array}$ & $\boldsymbol{R}_{0}(\Omega)$ & $\rho_{(\Omega \mathbf{m})}$ \\
\hline \multirow{3}{*}{ Cond. A } & $\begin{array}{c}\text { A1 } \\
\text { (Fig. 3.b) }\end{array}$ & $6.43^{*} 10^{-6}$ & $5^{*} 10^{-9}$ & $1.02 * 10^{-15}$ & $1.71 * 10^{6}$ & $2.72 * 10^{-4}$ \\
\hline & $\begin{array}{c}\mathrm{A} 2 \\
\text { (Figure S7.a.I) }\end{array}$ & $3.53 * 10^{-6}$ & $5 * 10^{-9}$ & $1.02 * 10^{-15}$ & $1.10 * 10^{6}$ & $3.18 * 10^{-4}$ \\
\hline & $\begin{array}{c}\mathrm{A} 3 \\
\text { (Figure S7.a.II) }\end{array}$ & $4.15^{*} 10^{-6}$ & $5 * 10^{-9}$ & $1.02 * 10^{-15}$ & $1.34 * 10^{6}$ & $3.30 * 10^{-4}$ \\
\hline \multirow{3}{*}{ Cond. B } & $\begin{array}{c}\text { B1 } \\
\text { (Fig. 3.c) }\end{array}$ & $2.35^{*} 10^{-6}$ & $60^{*} 10^{-9}$ & $2.26^{*} 10^{-14}$ & $26.13 * 10^{3}$ & $2.52 * 10^{-4}$ \\
\hline & $\begin{array}{c}\text { B2 } \\
\text { (Figure S7.b.I) }\end{array}$ & $4.64 * 10^{-6}$ & $60^{*} 10^{-9}$ & $2.26^{*} 10^{-14}$ & $61.08 * 10^{3}$ & $2.98 * 10^{-4}$ \\
\hline & $\begin{array}{c}\text { B3 } \\
\text { (Figure S7.b.II) }\end{array}$ & $4.53 * 10^{-6}$ & $60^{*} 10^{-9}$ & $2.26^{*} 10^{-14}$ & $42.71 * 10^{3}$ & $2.13 * 10^{-4}$ \\
\hline
\end{tabular}


Table S8. Data summary of $R_{0}$ and $R_{\mathrm{VRH}}(\mathrm{T})$ for representative single NT-3DFG devices synthesized under Conditions A and B.

\begin{tabular}{|c|c|c|c|c|c|c|c|}
\hline Sample & Device & $\boldsymbol{R}_{\mathrm{VRH}}(\mathbf{2} \mathbf{K})$ & $\boldsymbol{R}_{\mathrm{VRH}}\left(\mathbf{T}^{*}\right)$ & $\begin{array}{c}\mathbf{R}_{\mathrm{VRH}} \mathbf{( 3 0 0} \\
\mathbf{K})\end{array}$ & & $\boldsymbol{R}_{\mathbf{0}}$ & Trend \\
\hline Cond. A & $\begin{array}{c}\mathrm{A} 1 \\
\text { (Fig. 4.a) }\end{array}$ & $5.05 \mathrm{M} \Omega$ & $\sim \mathrm{R}_{0}$ & $30.16 \mathrm{k} \Omega$ & $<$ & $\begin{array}{c}1.71 \\
\mathrm{M} \Omega\end{array}$ & $\begin{array}{c}\text { MR has a } \\
\text { max near } \\
\mathrm{T}^{*}\end{array}$ \\
\hline Cond. B & $\begin{array}{c}\text { B1 } \\
\text { (Fig. 4.b) }\end{array}$ & $1.66 \mathrm{M} \Omega$ & $>>\mathrm{R}_{0}$ & $61.59 \mathrm{k} \Omega$ & $>$ & $\begin{array}{c}26.13 \\
\mathrm{k} \Omega\end{array}$ & $\begin{array}{c}\text { MR(T) is } \\
\text { monotonic }\end{array}$ \\
\hline
\end{tabular}




\section{References}

1. Rehr, J. J.; Kas, J. J.; Vila, F. D.; Prange, M. P.; Jorissen, K. Phys. Chem. Chem. Phys. 2010, 12, (21), 5503-5513.

2. Jorissen, K.; Rehr, J.; Verbeeck, J. Phys. Rev. B 2010, 81, (15), 155108.

3. Garg, R.; Rastogi, S. K.; Lamparski, M.; de la Barrera, S. C.; Pace, G. T.; Nuhfer, N. T.; Hunt, B. M.; Meunier, V.; Cohen-Karni, T. ACS Nano 2017, 11, (6), 6301-6311.

4. Giancoli, D. C.; Miller, I. A.; Puri, O. P.; Zober, P. J.; Zober, G. P., Physics: Principles with Applications. Pearson Education 2005, 4.

5. Mattevi, C.; Eda, G.; Agnoli, S.; Miller, S.; Mkhoyan, K. A.; Celik, O.; Mastrogiovanni, D.; Granozzi, G.; Garfunkel, E.; Chhowalla, M. Adv. Funct. Mater. 2009, 19, (16), 2577-2583.

6. Deokar, G.; Avila, J.; Razado-Colambo, I.; Codron, J.-L.; Boyaval, C.; Galopin, E.; Asensio, M.-C.; Vignaud, D. Carbon 2015, 89, 82-92.

7. Brownson, D. A.; Gómez-Mingot, M.; Banks, C. E. Phys. Chem. Chem. Phys. 2011, 13, (45), 20284-20288.

8. $\quad$ Ferrari, A. C.; Basko, D. M. Nat. Nanotechnol. 2013, 8, (4), 235-246.

9. Y Yu, K.; Bo, Z.; Lu, G.; Mao, S.; Cui, S.; Zhu, Y.; Chen, X.; Ruoff, R. S.; Chen, J. Nanoscale Res. Lett. 2011, 6, (1), 1.

10. Cançado, L.; Takai, K.; Enoki, T.; Endo, M.; Kim, Y.; Mizusaki, H.; Jorio, A.; Coelho, L.; Magalhaes-Paniago, R.; Pimenta, M. Appl. Phys. Lett. 2006, 88, (16), 163106.

11. Tuinstra, F.; Koenig, J. L. J. Chem. Phys. 1970, 53, (3), 1126-1130.

12. Hassoun, J.; Bonaccorso, F.; Agostini, M.; Angelucci, M.; Betti, M. G.; Cingolani, R.; Gemmi, M.; Mariani, C.; Panero, S.; Pellegrini, V. Nano Lett. 2014, 14, (8), 4901-4906.

13. Ferrari, A.; Robertson, J. Phys. Rev. B 2001, 64, (7), 075414.

14. Torrisi, F.; Hasan, T.; Wu, W.; Sun, Z.; Lombardo, A.; Kulmala, T. S.; Hsieh, G.-W.; Jung, S.; Bonaccorso, F.; Paul, P. J.; Chu, D.; Ferrari, A. C. ACS Nano 2012, 6, (4), 2992-3006. 15. Döbbelin, M.; Ciesielski, A.; Haar, S.; Osella, S.; Bruna, M.; Minoia, A.; Grisanti, L.; Mosciatti, T.; Richard, F.; Prasetyanto, E. A. Nat. Commun. 2016, 7, 11090.

16. Williams, D. B.; Carter, C. B. Transmission Electron Microscopy, Springer 1996.

17. Meyer, J. C.; Geim, A. K.; Katsnelson, M. I.; Novoselov, K. S.; Booth, T. J.; Roth, S. Nature 2007, 446, (7131), 60.

18. Stankovich, S.; Dikin, D. A.; Piner, R. D.; Kohlhaas, K. A.; Kleinhammes, A.; Jia, Y.; Wu, Y.; Nguyen, S. T.; Ruoff, R. S. Carbon 2007, 45, (7), 1558-1565.

19. Śliwińska-Bartkowiak, M.; Drozdowski, H.; Kempiński, M.; Jażdżewska, M.; Long, Y.; Palmer, J. C.; Gubbins, K. E. Phys. Chem. Chem. Phys. 2012, 14, (19), 7145-7153.

20. Rao, A.; Fung, A.; Dresselhaus, M.; Endo, M. J. Mater. Res. 1992, 7, (07), 1788-1794.

21. Biscoe, J.; Warren, B. J. Appl. Phys. 1942, 13, (6), 364-371. 